\title{
El monestir de Sant Cugat durant l'abadiat d'Odó (985-1010): la resposta a la nova estructuració comtal ${ }^{1}$
}

\author{
Joan Ruiz i Culell \\ Museu de Valldoreix. \\ Esglèsia, 9-11.08190 Valldoreix. Spain
}

\section{Resum}

Odó fou abat del monestir de Sant Cugat en una etapa de trànsit (985-1010). L'abat va revitalitzar el cenobi gràcies a l'adquisició de noves terres properes al monestir. Així, mitjançant d'intercanvis, donacions "pietoses” i vendes, construi un nucli patrimonial uniforme.

Abstract. The monastery of Sant Cugat during Odd's abbey (985-1010): The reply to new
county's structure

Od6 was a monastery of Sant Cugat's abbot in a transitional period (985-1010). The abbot revitalized the monastery with the acquisition of new lands situated next to the monastery. Therefore, thanks to interchanges, "piety" donations and sales he made a uniform patrimony.

Latac d'Al-Mansur als comtats catalans el 985 ha marcat una fita transcendent dins la història de Catalunya. S'ha volgut implicar aquesta data amb l'inici de la independència dels comtats catalans vers el regne franc, tot justificant la manca de suport per part del monarca davant la sol.licitud efectuada pel seu vassall, el comte Borrell $i$, fins $\mathrm{i}$ tot, s' ha pogut prendre aquesta data per marcar l'inici de la historiografia catalana. Dins el Cartoral de Sant Cugat ${ }^{2}$ apareixen mencions a aquest fet en diversos documents. Es tracta d'al-lusions explicatives i en cap cas necessàries, la voluntat de les quals no és altra que fixar en la memòria col-lectiva el fet concret. Aquests documents mostren de quina mane-

1. Aquest article prové del desenvolupament d'una comunicació presentada a les I Jornades de Joves Medievalistes del Vallès, amb el títol «Existeix una ideologia al voltant de l'adquisició de propietats durant l'abadiat d'Odó de Sant Cugat?n, la qual formarà part de les Actes de les mencionades Jornades.

2. El Cartoral de Sant Cugar, que es troba a l'Arxiu de la Corona d'Aragó, va ser editat per mossèn Josep Rius. En la scva edició, a més dels documents propis del Cartorah va afegir aquells que va trobar disseminats i que feien referència al monestir de Sant Cugat. Vegeu RuUS, Josep (1947). Carrulario de "San Cugarw del Vallés. 3 vol. Barcelona: CSIC. 
ra afectà -més que la ràtzia sarraïna d'Al-Mansur en concret-el perill musulmà, en una societat encara força vulnerable. Els comtats catalans (potser seria millor anomenar-los precatalans) es movien en un estadi de formació i consolidació, des del mateix moment que Guifred I aconseguí "cogovernar" amb els seus germans els territoris que les Assembles d'Attigny (870) i de Troyes (878) els havien concedit ${ }^{3}$. A P'inici del segle $\mathrm{X}$ es produí un fet cabdal: els comtes-funcionaris esdevingueren comtes-propietaris dels seus dominis i la funció comtal es convertí en hereditària. Potser aquest canvi tingué molta més transcendència - si volem trobar els origens de la independència de Catalunya - que la manca de resposta del rei franc a la sol-licitud d'ajut efectuat pel comte Borrell. Martí Aurell, tot basant-se en la importància de les relacions matrimonials com a eina estructuradora i gestora d'un territori, delimita l'espai temporal comprès entre l'any $800 \mathrm{i}$ el $930 \mathrm{com}$ l'època dels "casaments consanguinis» entre els diferents comtes catalans, fornidors d'una primera consciència comuna d'unitat. El sistema matrimonial que practiquen aquests comtes és definit per tres característiques: l'endogàmia, la isogàmia $i$ la proximitat. Els matrimonis endogamics afavoreixen la solidaritat entre els comtes i sobretot impedeixen l'intrusisme, protegint sobretot la unitat patrimonial familiar. $\mathrm{La}$ isogàmia, en relacionar conjuges d'un mateix rang, consolida el patrimoni i vertebra les relacions internes $\mathrm{i}$, finalment, la proximitat afavoreix la cohesió entre les diferents branques comtals, nascudes d'un tronc comút.

Seguint aquest autor, i entrant en l'època que afecta directament aquest estudi, Aurell proposa una segona etapa en l'estructuració territorial: 930-1080, època dels "casaments oberts". Tot havent-se assolit la finalitat de la primera fase - la implantació en el territori amb els "casaments consanguinis»els comtes "precatalans" dirigeixen les seves estratègies matrimonials cap a dos objectius importants. D'una banda, a través de l'exogàmia s'estableixen contactes amb l'exterior destinats a afavorir les relacions amb els territoris veïns, tant a nivell de col-laboració en les lluites contra els musulmans com per desenvolupar el seu expansionisme i, de l'altra, mitjançant la hipergàmia aniran desenvolupant un sistema de valors que vertebrarà les relacions internes de cada territori. El cas del comtat de Barcelona ha estat estudiat per José Enrique RuizDomènec ${ }^{5}$. El fenomen hipergàmic envolta les relacions entre el comte de Barcelona, Borrell, i el vescomte d'aquesta ciutat, Guitard. El comte cedeix dues de les seves filles - Riquilda i Ermengarda - a dos dels fills del vescomte -Udalard i Geribert-. Lobjectiu d'aquest acte inicial rau en la consciència que el comte té que el perill musulmà és més important que mai, a causa tant

3. D'ABADAL I DE VINYALS, Ramon (1958). Els primers comies catalans. Barcelona.

4. Aureli. I Cardona, Martí. (1991). Les Noces du Comte. Mariage et pouvoir en Catalogne (785-1213). París: Publications de la Sorbone, p. 50-51. Vegeu també: "Jalons por une enquête sur les estrategies matrimoniales des comtes catalans (DKe-Xle s.) n, dins Symposium Internacional sobre els Origens de Catalunya (segles vIII-XI), p. 281-364. Barcelona.

5. RUiz-DOMENEC, José Enrique (1985), Lestruchura feudal. Sistema de parentiu i teoria de lalianca en la societat catalana (c. 980-c. 1220). Barcelona: Edicions del Mall. 
del caràcter bel-ligerant del nou capitost sarraí - Al-Mansur- com de la manifesta descomposició del regne de qui l'ha de protegir. D'aquesta manera l'objectiu prioritari per a Borrell esdevindrà l'estructuració del seu patrimoni, del seu comtat. A través de la donació de les seves filles al vescomte - l'encarregat de la defensa del territori- $s$ 'iniciarà un ordenament intern de les funcions organitzatives. Udalard, el fill primogènit, serà l'encarregat de la defensa del territori; Geribert vetllarà pel patrimoni material de la seva família; finalment Adalbert, el fill que no rep cap dona del seu senyor, es mantindrà cèlibe i participarà decisivament en les accions militars vers els musulmans. Els fills de Guitard, tot seguint l'exemple que el comte els va proposar, casaren les seves filles amb els veguers dels castells de Sant Martí i de Castellvell de la Marca. Aquest sistema de relacions, en el qual el donador de dones és superior al prenedor, crearà implicitament un sistema d'obligacions i drets. Laparició, a partir d'aquests moments, dels llinatges i la seva fixació al territori implicarà que el control del patrimoni esdevingui d'una importància cabdal.

En aquest context de profundes transformacions creadores d'una nova realitat social és on hem de situar el govern de l'abat Odó. La ràtzia d'Al-Mansur del 985 fou extremament violenta per al monestir. Labat Joan $i$ una bona part de la comunitat de monjos moriren a les mans dels sarraïns ${ }^{6}$. D'entre els que sobrevisqueren, Odó fou escollit abat. Vint-i-cinc anys més tard, el 1010, participà en l'expedició que el comte Ramon Borrell organitzà vers Còrdova, la qual - a causa de les ferides rebudes - significà la fi dels seus dies.

L'abat Odó, personatge proper a la cort comtal barcelonesa i que per tant hauria de tenir coneixement dels canvis estructurals que el comte Borrell estava implantat, establí una transformació radical tant en l'estratègia adquisitiva del monestir com en el sistema per dur-la a terme. Durant els vint-i-cinc anys de la seva direcció santcugatenca, el model organitzador aristocràtic evolucionà de forma notable. Les aliances matrimonials entre els diferents llinatges configuraren una xarxa de control i organització del territori cada cop més sòlida ${ }^{7}$. La preocupació dels diferents caps dels llinatges no fou altra que la fixació dels límits territorials d'actuació de cadascun d'ells. Aquesta va ser la direcció que prengué en el seu govern l'abat Odó. La documentació existent en el Cartoral de Sant Cugat (edició de Rius) ens mostra clarament aquest canvi d'enfocament. Ja des dels temps de Guifred I, el monestir de Sant Cugat d'Octavià — nom medieval d'aquest cenobi- fou una important eina comtal per a l'organització dels territoris fronterers del Llobregat i del Penedès. Els seus dominis s'escamparen pels castells de Cervelló, d'Eramprunyà i d'Olèrdola, principalment. Dins la seva comarca natural, el Vallès, per les poblacions de

6. Feliu MONFORT, Gaspar (1982), uAl-Mansur, Barcelona i Sant Cugats, dins Acta Historica et Archaeologica Mediaevalia, núm. 3, p. 49-54. Barcelona.

7. Per entendre el funcionament intrinsec d'aquestes relacions de parentiu entre l'aristocràcia, vegeu: Rutz-DOMENEC, José Enrique (1984). La memoria de los feudales. Barcelona: Argot i «Système de parenté et théorie de l'alliance dans la société catalane (env. 1000 env. 1240)» dins Revue Historique, núm. 532, p. 305-326, 1979. 
la conca del riu Besòs i els seus afluents, com la Roca, Llerona, Palou, Perafica, Lliçà, Plegamans, Gallecs... Es tractava d'un domini dispers i relativament llunyà de l'enclavament monàstic. L'arribada d'Odó marca un punt d'inflexió en la trajectòria del monestir i es produeix una extraordinària revitalització en l'activitat del cenobi. Dels 431 documents que componen l'edició del Cartoral de Sant Cugat de l'inici fins al 1010, 261 pertanyen a les actuacions d'Odó. En aquest sentit s'hauria de mencionar la pèrdua de documentació produida per la destrucció de part de l'arxiu del monestir a causa de l'atac d'Al-Mansur. De tota manera, aquest fet ha estat relativitzat per la historiografia i malgrat que en el precepte, que Odó recapta del rei Lotari, consta la combustió de les escriptures - «...vel per scripturas aliorum Christi fidelium combustas.... ${ }^{8}-$ ens afegim a la reflexió de Xavier Bou quan afirma que així com els propis documents del monestir mencionen la desfeta de la ciutat de Barcelona, cap no fa referència a la destrucció del cenobi ${ }^{9}$ - exceptuant el precepte reial $\mathrm{i}$ un altre document en el qual es realitza una donació per recuperar els ornaments de l'església - ${ }^{10}$. Hem confeccionat un gràfic en el qual es mostren les adquisicions efectuades per l'abat Odó comparant-les a les fetes pels abats anteriors (figura 1).

Es pot observar clarament el canvi substancial de tendència. L'àrea geogràfica del Llobregat continua formant part del camp d'expansió del monestir, encara que amb lleugeres modificacions. La zona oriental del Vallès deixa d'interessar definitivament el monestir. En canvi, prenen valor d'una forma espectacular els llocs més propers al cenobi, començant pel mateix Sant Cugat - sobretot el terme d'Aiguallonga-, i seguint per Ripollet, Montcada i Reixac i Cerdanyola. Hem d'apuntar, però, que la diferència quantitativa que reflecteix el grâfic d'adquisicions no mostra la realitat en la seva totalitat. Segons el precepte de Lotari el monestir tenia certament propietats en aquests indrets - "...et in Agualonga et in Rioo Rubeo et in Cerdaniola et in Araona et in eorum terminis, domos, curtes, ortos, puteos, prata, pascua, vineas, terras cultas et incultas, per plura loca particulatim segregata.... ${ }^{11}$. Retinguem aqui l'expressió «....per plura loca particulatim segregata..... És a dir, el monestir ja estava implantat en aquesta zona, encara que no disposem dels documents que individualitzen les adquisicions, i que potser formaren part d'aquells que suposadament varen ser incendiats. D'aquesta manera, en la barra del graffic que mesura les propietats del monestir fins el 985 en els termes del Vallès Occidental haurien de figurar més propietats. El que sí és cert és que l'abat Odó tenia plena consciència que els dominis que pertanyien al monestir esta-

8. RuUs, Josep. Cartulario...., vol. I, doc. 173.

9. Xavier Bou escriu: eSi la destrucció hagué estat molt intensa, no seria més normal que hi haguessin més referències documentals als fets, de la mateixa manera que n'hi ha per Barcelona?n, BOU PALMES, Xavier (1985), „El monestir de Sant Cugat en el segle X, La formació del domini vallesà̀, dins Estudis Santcugatenes, núm. 5. p. 75. Monogràfic, Sant Cugat del Valles.

10. RuUs, Josep. Cartulario..., vol. I, doc. 255.

11. Rius, Josep. Cartulario.... vol. I, doc. 173. 


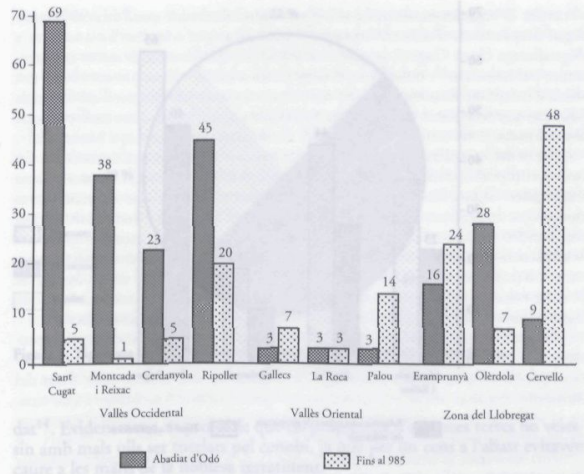

Figura 1. Adquísicions totals efectuades fins a l'arribada de l'abat Odó comparades amb les realizzades durant el seu mandat als llocs més importants.

ven disseminats, ja que així ho féu constar en la redacció del precepte reial. D'altra banda, gosem afirmar que les adquisicions que efectuà Odó sobre aquests indrets foren realment noves propietats, i no restauracions d'escriptures desaparegudes. L'anàlisi de la seva línia d'actuació així ens ho fa pensar.

La documentació que hem utilitzat per analitzar l'acció de l'abat ha estat acotada a aquella que ens proporciona informació sobre el Vallès Occidental, ja que com hem vist en el gràfic d'adquisicions, és en aquest indret on es produeix un canvi d'orientació del cenobi. Aquest recull ha proporcionat informació sobre 166 transaccions $^{12}$. En una primera ullada es constata que només la meitat del Vallès Occidental roman sota el domini del monestir, és a dir, la zona de Sant Cugat, Cerdanyola, Ripollet i Montcada i Reixac. Laltra meitat, la part de Rubi, Terrassa, Sabadell, resten fora del seu control.

12. Hem de puntualitzar que cadascuna de les propietats que passen a formar part del domini del monestir ha estat considerada una transacció. D'aquesta manera si en un document es realizza una donació de quatre terres, entenem que es tracta de quatre transaccions, tant si es troben localitzades en el mateix indret com si estan allunyades l'una de l'altra. 


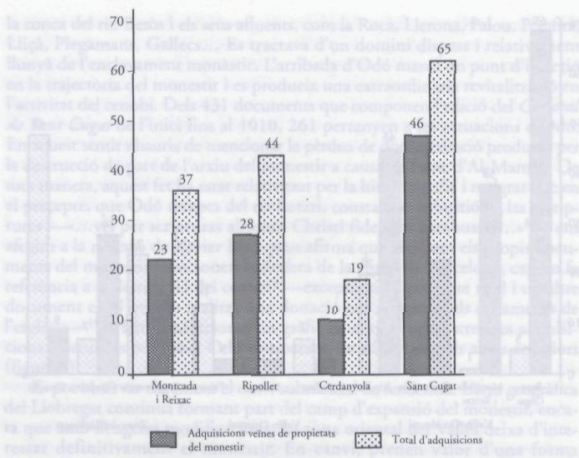

Figura 2. Adquisicions que tenen afrontacions amb propietats ja controlades pel monestir.

Per tal d'entendre el desenvolupament de la formació d'aquest domini hem d'abandonar definitivament la idea que aquest sigui el resultat de la suma de les donacions, permutes $i$ vendes que els fidels atorguen al cenobi en concepte de la seva religiositat ${ }^{13}$. La lectura directa de la documentació ens mostra certament com són els propietaris els que s'apropen al cenobi per tal d'efectuar una donació o de vendre o intercanviar tot o part del seu patrimoni. Res més lluny d'això, per tal de formar un cos compacte, un nucli patrimonial uniforme en el qual mai no pugui infiltrar-se cap element de la xarxa del poder laic, l'abat guiarà, meticulosament, les voluntats dels habitants de les propietats desitjades per tal que esdevinguin del control del monestir. Xavier Bou ja intueix aquesta possibilitat, malgrat que no s'atreveix a afirmar-la amb clare-

13. SALRACH, J. M., defensa aquesta idea en el seu article: „Formació, organització i defensa del domini de Sant Cugat en els segles X-XIls, dins Acta Historica ct Archaeologica Mediaevalia, núm. 13, p. 129-173, Barcelona, 1992. Diu així: aLes grans fortunes eclesiàstiques procedeixen de les petites, de laics i eclesiàstics, per un constant degoteig de propietats que s'accelera a la segona meitat del segle X i remet a partir de vers 1025 . En les donacions, dites pietoses, d'abans de 1025 es barregen, segurament, les motivacions religioses amb les econòmiques (potser endeutaments, recerca de protecció) s, p. 168. 


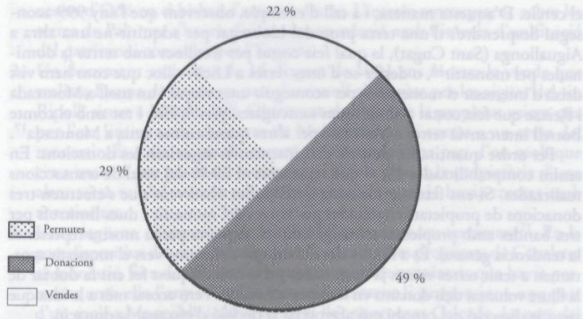

Figura 3. Tipologia de les adquisicions en percentatge sobre el total d'actuacions.

dat $^{14}$. Evidentment, és probable que els propietaris d'aquestes terres no veiessin amb mals ulls ser tutelats pel cenobi, ja que per un cens a l'abast evitaven caure a les mans de la noblesa terratinent.

Així doncs, l'objectiu prioritari del monestir es concentrarà en la recerca i adquisició de propietats que tinguin pel cap baix una afrontació amb altres ja controlades pel cenobi. Analitzant els documents podem obtenir les dades següents: a Sant Cugat, de les 65 propietats adquirides 46 compleixen aquesta intenció; a Cerdanyola, 10 sobre un total de 19; a Ripollet, 28 de 44 i a Montcada i Reixac, 23 de 37 (figura 2).

En termes percentuals podem afirmar que el $65 \%$ de les adquisicions efectuades s'inclouen en una línia d'actuació que busca la reagrupació del domini. I el mitjà que s'utilitzarà per aconseguir-ho serà d'una forma majoritària l'intercanvi. Hem localitzat 77 permutes, les quals representen un $49 \%$ de les actuacions de l'abat (figura 3 ). Veient les propietats que el monestir aconsegueix amb aquests intercanvis i les terres de les quals es desprèn no podem tenir cap mena de dubte de qui fou el promotor de l'acte. El monestir santcugatenc trobarà en les permutes una eina fabulosa per convertir propietats allunyades i sense cap interès en adquisicions valuosíssimes per anar tancant

14. Aquesta idea la planteja, molt subtilment, en forma de pregunta: «A ningú se li escapa Pinterès lògic que devia tenir el monestir en obtenir una vinya que estava situada al bell mig de les seves propietats, un interès que queda refermat pel substancial canvi operat en la imposició. Fins a quin punt es coercionava a alguns pagesos per a que lliuressin unes terres sobre les que el monestir tenia un interès especial? Es una qüestió sobre la que dificilment mai podrem donar una resposta., BoU, Xavier. «El monestir...n, p. 62-63. 
el cercle. D'aquesta manera, i a tall d'exemple, observem que l'any 999 aconsegui desprendre's d'una terra prop del Llobregat per adquirir-ne una altra a Aiguallonga (Sant Cugat), la qual feia costat per tres llocs amb terres ja dominades pel monestir ${ }^{15}$, o desfer-se d'unes terres a Lliçà - lloc que com hem vist deixà d'interessar el monestir - per aconseguir unes vinyes i un molí a Montcada $i$ Reixac que feia costat a altres terres santcugatenques ${ }^{16}$. Fins i tot amb el comte Borrell intercanvià terres a Montjüc per altres que el comte tenia a Montcada ${ }^{17}$.

Per ordre quantitatiu, després dels intercanvis segueixen les donacions. En tenim comptabilitzades 45 , el que representa el $29 \%$ del total de transaccions realitzades. Si ens fixem en la zona de Ripollet observem que s'efectuen tres donacions de propietats envoltades per vinyes del monestir i dues limítrofs per tres bandes amb propietats santcugatenques. Aquesta petita mostra representa la tendència general. És a dir, les donacions que s' efectuen vers el monestir acostumen a tenir terres veïnes ja dominades pel cenobi. Aquest fet ens fa dubtar de la lliure voluntat dels donants en les seves actuacions i ens acosta més a la idea que sigui la direcció del cenobi qui afavoreixi la decisió d'efectuar la donació.

Finalment parlarem de les vendes. Tenim localitzades 34 vendes, que representen el $22 \%$ de les adquisicions de l'abat Odó. Deu d'aquestes vendes formen part d'un grup de propietats que no tenen cap delimitació amb altres del monestir. Aquesta situació ens demostra que de la mateixa manera que existia la voluntat de compactar el domini monàstic també es tractava d'anar augmentant la presència santcugatenca en els llocs d'interès.

Fins aquí hem analitzat l'adquisició directa, és a dir, aquella manera d'ampliar el domini del cenobi aconseguint amb una sola actuació la propietat desitjada. Passarem ara a presentar un segon sistema: l'adquisició diferida, l'adquisició a llarg termini. En aquest cas una sèrie d'actuacions que poden semblar independents l'una de l'altra es converteixen en una unitat d'acció. Aquesta unitat d'acció tindrà uns objectius que s'aniran complint al llarg d'un període de temps, i que fructificaran finalment en els resultats desitjats pel cenobi. Un exemple molt aclaridor ens el mostren el conjunt de les transaccions que efectuen Mel, Gotmar, Emma i l'abat Odón ${ }^{18}$. Les presentarem per ordre cronologic:

1. L'any $992 \mathrm{Mel}$ i Odó efectuaren una permuta de possessions ${ }^{19}$. El monestir adquiri set propietats a Palomar (actualment Sant Andreu de Palomar, barri de la ciutat de Barcelona) $i$ a canvi entregà cases $i$ terres a Canaletes, lloc de Cerdanyola i important nucli de control del cenobi. Aquestes propietats confrontaven amb possessions del bisbe Gotmar de Girona, que fou l'ante-

15. Rus, Josep. Carrulario..., vol. 1, doc. 345.

16. RuUs, Josep. Carrulario...., vol. 1, doc. 233.

17. RuUs, Josep. Cartulario..., vol. 1, doc. 297.

18. Per conèixer millor la relació entre Mel i l'abat Odó vegeu Ruzz I CuLeı, Joan, eL'estratègia de l'abat Odó de Sant Cugat en l'adquisició de propietats a partir d'un testameno, dins Gausac, núm. 6, p. 43-48, Sant Cugat del Valles, 1995.

19. RiUs, Josep. Cartulario..., vol. I, doc. 276. 
cessor d'Odó en el bisbat d'aquesta ciutat. Linterès santcugatenc sobre les terres de Palomar s'haurà d'entendre en relació amb l'interès d'unificació del patrimoni controlat per l'Església.

2. Un document amb data de 16 d'agost de 1001 ens mostra la venda que realitza Emma de la quarta part d'un molí alimentat per les aigües del riu Ripoll, situat a Montcada ${ }^{20}$. Observant els límits de la propietat veiem que per l'est limita amb una terra de Mel i pel sud fa costat a un terra del monestir. És a dir, el cenobi comença a controlar una part d'un molí que era a tocar d'una possessió monàstica, i alhora coneix la propietària d'una altra terra també veïna a aquest moli amb la qual ja havia tractat amb anterioritat.

3. L'any següent, el setembre de 1002 , Mel redacta el seu testament ${ }^{21}$. En la part dispositiva del document ordena lliurar les seves propietats de Canaletes al monestir. És a dir, el cenobi recupera aquelles propietats que havia permutat amb ella l'any 992, i, a més, el testament li proporciona una part d'un molí a Montcada i altres terres al lloc anomenat Calçada. La part del molí que cedeix al monestir està directament relacionada amb la part que el monestir comprà a Emma l'any anterior. És a dir, que el cenobi ja estava implantat en aquesta zona, i amb la donació testamentària de Mel i la compra que fa a Emma consolida i aglutina sensiblement el control sobre aquest moli.

4. Finalment, l'any 1005 un personatge anomenat Gotmar dóna al monestir una possessió a Palomar ${ }^{22}$ que feia costat a les que Mel havia rebut en la permuta amb l'abat Odó i que posteriorment retornà al cenobi a través del seu testament.

Així doncs, s'ha pogut observar que des de l'any 992, en què s'efectua l'intercanvi de propietats entre Mel i Odó, fins a l'any 1005, en què Gotmar dóna una possessió a Palomar, el monestir ha augmentat i agrupat considerablement el seu patrimoni. La inversió inicial, que suposà la permuta de les propietats a Canaletes, ha fructificat $i$ ha donat com a resultat:

1. La recuperació d'aquestes terres.

2. La compra d'una part d'un molí a Montcada que era propietat d'Emma.

3. Laugment patrimonial degut a la resta del testament de Mel: és a dir, terres a Calçada i el control quasi total del moli de Montcada.

4. Ladquisició de sis terres a Palomar com a resultat de la permuta realitzada amb Mel.

5. Lapropiació d'una altra terra a Palomar que feia costat a les ja adquirides, per donació de Gotmar.

20. Ruus, Josep. Cartulario.... vol. II, doc. 360.

21. Ruus, Josep. Carrulario.... vol. II, doc. 377.

22. RIus, Josep. Carrulario...., vol. II, doc. 399. 
Hem de pensar que l'adquisició diferida fou la forma d'actuació que més utilitzà l'abat del monestir en la seva política administrativa de propietats, i d'aquesta manera quan trobem que el cenobi aconsegueix una parcel-la que momentàniament no té cap altra terra pròpia per veina, probablement la documentació posterior ens fornirà de la documentació necessària per posar en relació aquesta terra amb d'altres que el cenobi anirà aconseguint.

Hem comentat a l'inici que una de les raons fonamentals d'aquest sistema administratiu que portà a Odó a aglutinar i compactar les possessions del monestir fou la d'impedir que la creixent noblesa laica pogués esmicolar el puixant patrimoni santcugatenc. En aquest sentit serà Guitart, l'abat que succeirà en el càrrec a Odó, qui s'encarregarà de consolidar aquest patrimoni davant de l'intent cada vegada més intens de l'aristocràcia barcelonina, i sobretot vescomtal, de recuperar les propietats cedides al monestir. Diferents plets portaran el monestir a enfrontar-se amb el vescomte Geribert o amb Adelaida, esposa del veguer de Sant Martí, pel control de determinades possessions. Aquesta situació, però, ja apareixerà durant el mandat d'Odó. L'abat haurà de fer valer els seus arguments contra l'intent del veguer Sunifred de Rubi d'apropiar-se del curs de les aiguies de la riera de Xercavins que alimentaven uns molins santcugatencs $^{23}$. Odó aconseguirà guanyar el plet gràcies al control total sobre les seves possessions.

L'abat Odó fou un home del seu temps. El seu mandat com abat del monestir de Sant Cugat es veié inserit en un moment històric en el qual es produïren profundes transformacions. La formació, delimitació i fixació del patrimoni de les famílies aristocràtiques laiques obligaren el monestir a respondre de la mateixa manera per tal de mantenir-se i consolidar el seu "estatus" dins el comtat de Barcelona. Odó així ho va entendre i desenvolupà una organizzació interna del seu patrimoni tot abandonant l'interès per les propietats llunyanes del monestir i fent prevaler d'una forma notable la voluntat d'assolir un control directe dels voltants geogràfics del cenobi. Hem pogut observar com utilitzà majoritàriament les permutes per tal d'aghutinar el seu patrimoni, tot desfentse de les propietats allunyades. D'altra banda, podem afirmar que la iniciativa en l'adquisició d'una determinada propietat partí sempre de l'interior del monestir. Les donacions que els documents defineixen com a "pietoses" perden aquest sentit quan s'analitzen en conjunt, formant part d'una intenció global sobre un territori i sota una línia d'actuació predeterminada pel cenobi. Veiem, doncs, com darrera de l'actuació de l'abat Odó existeix una ideologia de poder que, alhora, afavorirà les relacions entre els diferents establiments eclesiàstics per tal de fer un front comú vers el poder laic. La ideologia de l'abat Odó, inserida en un context històric de trànsit, guiarà el monestir cap a una nova realitat. L'abat Odó crearà els sòlids fonaments per construir un important centre de poder.

23. RiUS, Josep. Cartulario..., vol. I, doc. 317. 